\title{
Memorias de ciudadanía. Los avatares de una polis golpeada. La experiencia uruguaya de Amparo Menéndez-Carrión
}

(Montevideo: Fin de Siglo. 2015).

\section{Gonzalo Ghio $^{1}$}

El libro que a continuación presentaré no es precisamente un libro, es una obra, una enorme obra. Bastan algunos datos cuantitativos: tres tomos, 15 capítulos, 1.482 páginas. Pero también lo muestra una rápida revisión de sus contenidos: filosofía política, teoría social y política, estudio historiográfico, análisis de casos, investigación politológica empírica.

El tema de esta obra son los "avatares de la polis uruguaya", es decir, los procesos históricos de configuración, fortalecimiento, hegemonía y luego embate y socavamiento de la polis en Uruguay. Pero, ¿qué es la polis? La polis es un concepto -y una problemática- que elabora la autora para hacer referencia a una lógica discursiva que se despliega en el terreno cultural y material, que conjuga igualdad y pluralismo en los entornos de convivencia donde los diversos-extraños pueden convivir, "serestar ahí", con los otros, en condiciones de igualdad y reconocimiento mutuo. La polis es así una lógica discursiva que, cuando se vuelve hegemónica, posibilita que los espacios públicos sean propicios para que asistan y convivan los "distintos pero iguales"; en resumen, es un discurso que habilita la vida en común entre extraños. Esto tiene implicancias materiales y culturales, ya

Sociólogo Universidad de Chile, Magister en Estudios Internacionales Universidad de Chile, Postgrado en Demografía Celade-Cepal, Dr(c) en Ciencias Sociales Universidad de Chile, becario CONICYT N² 21140742. Santiago, Chile. Contacto: gonzaloghio@gmail.com. 
que la polis actúa tanto como un freno de las diferencias de clase como un estímulo a la convivencia respetuosa entre diversos que son anónimos entre sí, fortaleciendo lo público e impulsando la vida colectiva. Cabe señalar que la polis se concretiza en espacios públicos que necesariamente se despliegan en los niveles que van desde lo nacional a lo local, ya que implica un ser y un estar con otros en los lugares concretos donde se produce la convivencia, por lo que la autora reivindica la importancia de lo nacional y lo local como los entornos concretos donde se desenvuelve la vida cotidiana de la inmensa mayoría de la población -de todos, salvo de las elites transnacionalizadas-, y la necesidad de resguardar estos sitios frente a los proyectos globalizadores que les restan relevancia -por ello la autora inicia la obra preguntándose por el lugar de la polis en la llamada "era global"-.

Sobre la base de esta problemática, la obra se despliega en los niveles teórico, histórico y de análisis empírico, los cuales son tratados con mayor o menor centralidad en los diferentes capítulos. En relación con el aspecto teórico-conceptual, hay un notable esfuerzo para definir la problemática, la perspectiva teórica y por operacionalizar los conceptos necesarios para el análisis. La autora recurre a la filosofía política y a diferentes escuelas de teoría social y política, lo que la lleva a poner en juego, de manera muy ordenada y prolija, la interdisciplinariedad y el eclecticismo. Así, trabaja y elabora sus conceptos utilizando pensadores como Arendt, Bourdieu, Foucault, Gramsci, Heidegger, Isin, entre otros, dando cuenta de múltiples debates que se han dado a partir de sus obras. Más allá del acuerdo que se pueda tener con sus planteamientos, es imposible dejar de reconocer el enorme rigor con el que la autora revisa a estos pensadores y varios de los debates que han generado. Incluso, un aporte accesorio pero muy valioso de la obra es que se detiene en entregar una enorme cantidad de referencias y bibliografía pertinente para cada uno de los múltiples debates que revisa, por lo que puede ser muy útil para entrar en los cuerpos de literatura de estos debates. Sin pretender abordar la descripción del desarrollo teórico, cabe des- 
tacar que hay varios planteamientos y propuestas conceptuales que indudablemente tienen bastante originalidad y que tensionan las perspectivas convencionales, ya sean los conceptos novedosos que propone la autora como "polis" -al que ya me referí- o "nodo medio" -con el que hace referencia a todos los diversos actores, ciudadanos, que confluyen en la polis, trascendiendo la clásica visión de la "clase media" como espacio de confluencia social-, o conceptos clásicos ampliamente empleados en el análisis sociopolítico, a los que da usos no convencionales, como "democracia", "ciudadanía", "poder", "discurso", "lo público", "lo político", etc.

En el ámbito histórico, la obra relata la emergencia, despliegue hegemónico y luego la erosión y retroceso de la polis en Uruguay. En el relato, la autora entrecruza factores nacionales, internacionales y globales, tanto en relación con las condiciones de posibilidad de la emergencia de la polis durante la Colonia y el siglo XIX, como de su hegemonía durante la primera mitad del siglo $\mathrm{XX}$, y finalmente de los embates que sufre y que la debilitan a partir de la segunda mitad del siglo XX. Así, por ejemplo, se tematiza la tardía colonización, la falta de interés de los imperios español y británico en los recursos económicos uruguayos, la inexistencia de una fuerte oligarquía y la amplia inmigración entre las condiciones que posibilitaron el fortalecimiento de la polis. En cuanto al proceso de erosión de la polis, se postula la centralidad de la guerra fría y la lógica del amigo-enemigo que se despliega en todo el mundo, que es fomentada, e incluso exigida, por Estados Unidos en todos los países que están en su esfera de influencia. Uruguay no puede escapar a esta lógica, la cual es exacerbada por la dictadura militar, que la aplica a través de la doctrina del enemigo interno, con la persecución política y su campaña de exterminio, tortura y exilio. A este factor se agrega el proyecto global neoliberal, internalizado por parte de las elites políticas y económicas del país, que fomenta el individualismo y el desprecio por lo público, y exacerba y legitima las desigualdades económicas, proyecto que además tiene un alcance global, 
que es impulsado por el enorme poder de los grandes capitales globales y tiene el respaldo de elites intelectuales y políticas transnacionalizadas.

En cuanto al análisis empírico, la autora busca, por una parte, analizar la trayectoria de diversos sitios de politicidad, sitios en los que se despliegan las lógicas políticas de la polis y de su némesis autoritaria-neoliberal. Desde esta problemática, se realizan cuatro estudios sobre sitios particulares: un sindicato que lucha por reabrir una fábrica quebrada bajo su control, una federación de cooperativas de viviendas que recurre a la propiedad colectiva, un gremio de propietarios de pequeños almacenes de barrio que lucha contra la penetración de los grandes supermercados, y el campo del teatro. Por otra parte, por medio de un amplio conjunto de entrevistas en profundidad a "hacedores de opinión", entre los que incluye un variado repertorio de líderes -empresarios, políticos, intelectuales, artistas, dirigentes sociales, deportistas, figuras de medios de comunicación, etc.-, la autora analiza los relatos que actualmente comparecen acerca de Uruguay, y diagnostica su condición presente y el espacio que ocupa la polis y su antagonista discursivo, el autoritarismo-neoliberalismo. Las entrevistas a los actores buscan comprender las visiones ideológicas que sustentan sus discursos y acciones, y las lógicas que promueven respecto de lo público. De esta manera, quienes se interesan por el uso de la etnografía y de métodos cualitativos para el análisis empírico de procesos políticos, encontrarán en este estudio un ejemplo de una rigurosa aplicación de estas técnicas.

Desde estos tres niveles se llega a la condición presente de la polis en Uruguay y las luchas políticas que se dan sobre ella. Uruguay es analizado como un espacio discursivo y de relaciones de poder, donde la polis está sitiada por las secuelas del autoritarismo y la lógica neoliberal. Estas fuerzas son articuladas discursivamente por el determinismo culturalista, que culpabiliza la cultura uruguaya por lo que consideran como obstáculos para el desarrollo. Así, en la actualidad, habría un choque entre dos lógicas discursivas, la de la polis y la del autoritarismo- 
neoliberalismo, que chocan en sus interpretaciones del presente y del pasado del país, así como en sus expectativas del futuro. Sin embargo, este choque es entre fuerzas desequilibradas. Por una parte el embate a la polis es muy potente, porque hace parte de una hegemonía global, la lógica neoliberal, que mediante su discurso logra producir un diagnóstico del presente y un proyecto de futuro, en tanto los defensores de lo público carecen de este diagnóstico y de un proyecto claro. En relación a este punto cabe señalar que la autora considera que la polis no fue un proyecto político conscientemente elaborado y buscado, no fue producto de estrategias desplegadas por la clase dominante, por las elites políticas o cualquier otro actor. La polis fue producto de innumerables acciones de diversos actores, entre los que se cuenta parte de las elites y clases dominantes, que la fueron forjando a través del tiempo con sus prácticas cotidianas, particularmente por medio de sus interacciones en los diversos espacios públicos, que conformaron formas de estar con los otros que a su vez produjeron una lógica discursiva que los hilvanó. Por el contrario, la lógica autoritaria-neoliberal responde a un proyecto político consciente, planificado, estratégicamente desplegado en todo el mundo, que se concretiza en los diversos países, entre ellos Uruguay, respaldado por clases y elites transnacionales y nacionales que detentan enormes recursos. De esta manera, el neoliberalismo se presenta en la actualidad como un proyecto de transformación, de "modernización", en tanto los defensores de la polis suelen apelar a la nostalgia por un pasado perdido, y su crítica al neoliberalismo aparece como conservadora. Por ello la necesidad que plantea la autora de reideologizar el debate político, y de incluir en él los problemas propios de la polis, la "calidad y textura" de los espacios públicos y de las formas de convivencia entre extraños.

Luego de este breve relato de esta enorme obra, me parece relevante resaltar la importancia que puede tener ésta para el análisis politológico chileno. Me detendré en tres temas. Por una parte, la autora plantea varias cuestiones para repensar, o pensar 
desde nuevas perspectivas, la actual situación política que enfrentan las diversas sociedades a escala mundial. La centralidad del neoliberalismo en el asedio de la polis sitúa a Uruguay en un proceso global, por lo que el país es entendido como un caso notable para mirar los procesos en torno a lo público y a los problemas relacionados con la convivencia entre extraños. El énfasis en la capacidad que tienen los espacios sociales para posibilitar o dificultar la convivencia es una perspectiva que cobra una notable relevancia en un momento en el cual temas como la migración y la religión se han posicionado en el centro del debate político, particularmente en las sociedades del centro del sistema mundial, es decir, en aquellas que siempre se han usado como modelos socioculturales e ideológicos en América Latina y Chile. En este contexto, el estudio también enfatiza la fuerte incidencia del neoliberalismo, no solo como modelo de desarrollo económico que profundiza las desigualdades ya muy amplias que caracterizan la región, sino también como ideología que legitima dichas desigualdades, que promueve la solución individual de los problemas cotidianos, que mantiene un discurso que menoscaba lo público y, particularmente, que ha promovido la alienación de las elites y clases dominantes de los contextos nacionales, factores que minan las posibilidades de mantener contextos de convivencia plurales e igualitarios.

Por otra parte, desde la perspectiva que plantea la autora, posiblemente el Chile de la década de 1980 en adelante puede ser considerado como un caso que está en las antípodas de la polis uruguaya de la primera mitad del siglo XX, que, según la autora, generó un contexto especialmente propicio para la convivencia entre extraños en un contexto plural e igualitario. Sería interesante utilizar esta perspectiva para analizar las implicancias que ha tenido sobre la sociabilidad, sobre la producción y uso de los espacios públicos, el éxito del neoliberalismo en el caso nacional, y particularmente la difusión de la ideología neoliberal como cultura hegemónica en Chile a partir de los años noventa. Así, la perspectiva propuesta en esta obra puede arrojar nuevas luces 
sobre el Chile contemporáneo, acerca de las formas de producción de lo público, incluso respecto de la construcción material de nuestras ciudades, barrios y espacios de encuentro, donde se materializa la ideología y economía neoliberal y se concretiza el tipo de sociabilidad y politicidad que fomenta.

Por último, el tercer elemento que quisiera destacar, ampliamente relevante para la Sociología, la Ciencia Política y las Ciencias Sociales chilenas, interesadas por lo político, es que esta obra, explícitamente, busca ampliar el horizonte del análisis político. La problematización de lo político que plantea la autora trasciende por mucho las acciones de estadistas, políticos, partidos, militares, sindicatos, asociaciones empresariales y grupos de presión de cualquier tipo, trasciende al sistema político y sus actores. Sin desconocer la enorme importancia de estos actores, e incluyéndolos continuamente en el estudio, su atención en las formas de producción de lo público y de la convivencia social hace que se entienda como políticos a todos aquellos involucrados en ella. Así, la producción de los espacios compartidos y de la convivencia que se da en ellos, es una tarea en la que se ven envueltos un amplísimo conjunto de actores, todos los cuales son entendidos como "políticos" en tanto participan en dicha producción colectiva. Sin embargo, la autora no cae en la ingenuidad de considerar que todos participan e inciden de manera igualitaria en los entornos comunes -ilusión promovida desde grandes intereses que buscan legitimar sus intervenciones mediante mecanismos de "participación ciudadana"-. En este contexto, es muy interesante la definición que se plantea de los "hacedores de opinión", ya que, si bien se entiende que lo público y las formas de convivencia son construidas por una enorme pluralidad de actores, también se reconoce que determinadas elites tienen un impacto significativamente mayor que el resto de los ciudadanos. Por ello la autora entrevista a un amplio conjunto de "hacedores de opinión" que, desde sus diferentes espacios, influyen en la configuración de lo público. 
Los Avatares de una Polis Golpeada, de Amparo Menéndez-Carreón, presenta un arsenal conceptual que permite plantear problemáticas ampliamente relevantes para repensar la actualidad política nacional y mundial, y análisis históricos y empíricos que muestran el potencial de dichas problemáticas. Esto hace que sea una obra de gran potencial para la sociología, la ciencia política y las ciencias sociales en general, particularmente en Chile, considerando el escenario nacional contemporáneo. 